\title{
Editorial
}

International Archives of
Allergy
Immunology

\section{MicroRNA: Endotyping United Airways?}

\author{
Asunción Martínez-Antón ${ }^{\mathrm{a}, \mathrm{b}}$ Joaquim Mullol ${ }^{\mathrm{a}-\mathrm{c}}$ \\ ${ }^{a}$ Clinical and Experimental Respiratory Immunoallergy, Institut d'Investigacions Biomèdiques August Pi I Sunyer \\ (IDIBAPS), ${ }^{\mathrm{b}} \mathrm{CIBER}$ de Enfermedades Respiratorias and GA² LEN (Global Allergy and Asthma European Network), and \\ ${ }^{\mathrm{C}}$ Rhinology Unit and Smell Clinic, Otorhinolaryngology Department, Hospital Clínic, Barcelona, Spain
}

Allergic rhinitis (AR) is a significant health problem because of its high prevalence (10-50\% of the population) and impact on patients' symptoms and quality of life [1]. To fully understand this impact, its relation to other upper and lower respiratory diseases, particularly asthma, should be taken into account, since up to $80 \%$ of the asthmatic patients present with concomitant AR [2]. Both diseases involve IgE-mediated mechanisms and can be triggered by similar allergens, including mold, animal dander and house-dust mites. Sustained airway inflammation associated with marked changes in gene and protein expression under fine-tuned regulation is a hallmark of AR. For this reason, a better understanding of the mechanisms involved in inflammatory gene expression regulation in $\mathrm{AR}$, whether associated with asthma or not, is critical for the development of new therapy approaches. A group of novel regulators of gene expression, purported to be involved in the modulation of the inflammatory process of diseases such as AR and asthma, are the socalled microRNAs (miRs).

MiRs are short, single-stranded, noncoding RNAs of 20-23 nucleotides that downregulate gene expression by binding to the $3^{\prime}$-untranslated region of their target mRNAs, which induce their degradation or impair their translation [3]. Given their very short complementarity to the target mRNA (6-8 nucleotides), a single miR can target hundreds of genes, and individual genes might be targeted by multiple mRNAs, adding complexity to the regulatory network between miRs and target genes [4]. MiRs are phylogenetically well conserved [5], which implies that they play an important role in biological processes. In fact, they are thought to regulate more than $30 \%$ of all protein-coding genes [6] and have been found to be involved in the regulation of development [7], proliferation [8], differentiation [9], apoptosis [10] and immune response [11].

The use of miR microarrays makes it possible to perform profiling studies that evaluate the differences between healthy and pathological tissues, treated and untreated samples and undifferentiated and differentiated cells [12]. Moreover, this systematic screening approach provides us with a starting point for the identification of new miR functions. Recent studies have identified miR profiles in multiple allergic inflammatory diseases, including asthma [13-16], eosinophilic esophagitis [17] and atopic dermatitis [18]. Although the evaluation of miR expression and function in AR patients has received little attention, a growing number of publications have

\section{KARGER}

E-Mail karger@karger.com

www.karger.com/iaa (c) 2014 S. Karger AG, Base

$1018-2438 / 14 / 1641-0010 \$ 39.50 / 0$
Correspondence to: Dr. Joaquim Mullo

Rhinology Unit and Smell Clinic, ENT Department

Hospital Clínic, Villarroel 170

ES-08036 Barcelona (Spain)

E-Mail jmullol@clinic.ub.es 
started to reveal the role of $\mathrm{miR}$ in the regulation of the inflammatory and immunological processes associated with AR [19].

In a recent issue of International Archives of Allergy and Immunology, Suojalehto et al. [20] examine several inflammatory markers and $\mathrm{miR}$ profiles in the nasal $\mathrm{mu}-$ cosa of long-term asthmatic patients with/without concomitant AR. Their study population consisted of 150 male individuals, including 117 asthmatic patients (persistent or nonpersistent asthma) and 33 control subjects. Around $80 \%$ of the asthmatic patients suffered from concomitant AR. Nasal mucosa samples were obtained from patients and controls for the assessment of miR expression.

Focusing on a group of miRs previously reported as differentially expressed in AR or related to inflammatory and immunological responses, the authors found that 10 miRs were differentially expressed in asthmatics and controls, independently of concomitant AR. In asthma patients, some were upregulated (mir-143, mir-187, mir498, mir-874 and mir-886-3p) and some were downregulated (let-7E, mir-18a, mir-126, mir-155 and mir-224) [20]. A potential reason for the absence of differences between asthmatic patients with and without AR might be the fact that the study was performed out of pollen season, and so patients were mainly presenting chronic symptoms in nasal mucosa rather than acute allergic reactions. As such, the visual analogue scale scores of nasal symptoms were low and no changes in the number of infiltrated eosinophils or Th2- and Th17-cytokine expression were found in the nasal mucosa; this corresponds with the absence of allergen exposure. Notwithstanding, mir-187 and mir-498 showed a remarkable but nonsignificant increase in the asthmatic patients with concomitant AR compared to the non-AR patients. Interestingly, these two miRs were previously found to be decreased in the nasal mucosa of AR compared to non-AR patients, in a group undergoing surgery for nasal obstruction [21].
This discrepancy in results might be due to differences in the population or samples used in both studies, chronic but mild inflammation [20] or ongoing severe inflammation [21] of the nasal mucosa.

To further analyze whether the changes observed in the miRs studied were useful in endotyping asthma severity, the authors analyzed two subgroups: nonpersistent and persistent asthma. Although no significant differences in $\mathrm{miR}$ expression were found in relation to asthma severity, a tendency towards greater differences was observed in those patients with more severe asthma. In a previous study by Williams et al. [13], no significant changes were found in the expression of $227 \mathrm{miRs}$ in the airway biopsies of patients with mild asthma, probably due to the mildness or to the fact that samples were not taken during an episode of asthma exacerbation. On the other hand, a significant increase (mir-21, mir-126, mir145, mir-106a, mir-221 and mir-485-3p) or decrease (let7, mir-146a and mir-146b) in miR expression has been described in relation to asthma, when asthma mice models or human samples from asthmatic patients exposed to allergens were used [22].

In conclusion, the study by Suojalehto et al. [20] describes small changes in a small number of miRs when asthmatic patients were compared to nonasthmatics. These changes were mainly in the opposite direction to those described in previous reports $[21,23]$, where samples were collected from patients experiencing acute allergic inflammation. In this sense, this study, together with previous publications, reveals the importance of the airway inflammatory stage at the time of sample collection in order to detect the changes in miR expression and correlate them correctly with the different activation stages of allergic diseases. In conclusion, the miRs differentially expressed in this study might be considered potential biomarkers of chronic rather than acute airway inflammation.

\section{References}

MicroRNA: Endotyping United Airways
1 Bousquet J, Khaltaev N, Cruz AA, Denburg J, Fokkens WJ, Togias A, et al: Allergic Rhinitis and Its Impact on Asthma (ARIA) 2008 update (in collaboration with the World Health Organization, GA(2)LEN and AllerGen). Allergy 2008;63(suppl 86):8-160.

-2 Cruz AA, Popov T, Pawankar R, Annesi-Maesano I, Fokkens W, Kemp J, et al: ARIA Initiative Scientific Committee. Common characteristics of upper and lower airways in rhinitis and asthma: ARIA update, in collaboration with GA(2)LEN. Allergy 2007;62(suppl 84):1-41.
3 He L, Hannon GJ: MicroRNAs: small RNAs with a big role in gene regulation. Nat Rev Genet 2004;5:522-531.

4 Bartel DP: MicroRNAs: target recognition and regulatory functions. Cell 2009;136:215-233.

5 Christodoulou F, Raible F, Tomer R, Simakov O, Trachana K, Klaus S, et al: Ancient animal microRNAs and the evolution of tissue identity. Nature 2010;463:1084-1088.

-6 Filipowicz W, Bhattacharyya SN, Sonenberg $\mathrm{N}$ : Mechanisms of post-transcriptional regulation by microRNAs: are the answers in sight? Nat Rev Genet 2008;9:102-114. 
7 Karp X, Ambros V: Encountering microRNAs in cell fate signaling. Science 2005; 310:1288-1289.

-8 Bueno MJ, Perez de Castro I, Malumbres M: Control of cell proliferation pathways by microRNAs. Cell Cycle 2008;7:3143-3148.

$>9$ Chen CZ, Li L, Lodish HF, Bartel DP: MicroRNAs modulate hematopoietic lineage differentiation. Science 2004;303:83-86.

10 Xu P, Guo M, Hay BA: MicroRNAs and the regulation of cell death. Trends Genet 2004; 20:617-624.

11 Liston A, Linterman M, Lu LF: MicroRNA in the adaptive immune system, in sickness and in health. J Clin Immunol 2010;30:339-346.

-12 Martinez-Anton A, Sokolowska M, Kern S, Davis AS, Alsaaty S, Taubenberger JK, et al: Changes in microRNA and mRNA expression with differentiation of human bronchial epithelial cells. Am J Respir Cell Mol Biol 2013;49:384-395.
13 Williams AE, Larner-Svensson H, Perry MM, Campbell GA, Herrick SE, Adcock IM, et al: MicroRNA expression profiling in mild asthmatic human airways and effect of corticosteroid therapy. PLoS One 2009;4:e5889.

14 Jardim MJ, Dailey L, Silbajoris R, Diaz-Sanchez D: Distinct microRNA expression in human airway cells of asthmatic donors identifies a novel asthma-associated gene. Am J Respir Cell Mol Biol 2012;47:536-542.

15 Rebane A, Akdis CA: MicroRNAs: essential players in the regulation of inflammation. J Allergy Clin Immunol 2013;132:15-26.

16 Rebane A, Akdis CA: MicroRNAs in allergy and asthma. Curr Allergy Asthma Rep 2014; 14:424-432.

17 Lu TX, Sherrill JD, Wen T, Plassard AJ, Besse JA, Abonia JP, et al: MicroRNA signature in patients with eosinophilic esophagitis, reversibility with glucocorticoids, and assessment as disease biomarkers. J Allergy Clin Immunol 2012;129:1064-1075.

18 Sonkoly E, Wei T, Janson PC, Saaf A, Lundeberg L, Tengvall-Linder M, et al: MicroRNAs: novel regulators involved in the pathogenesis of psoriasis? PLoS One 2007;2:e610.
9 Zhang X-H, Zhang Y-N, Liu Z: MicroRNAs in chronic rhinosinusitis and allergic rhinitis. Curr Allergy Asthma Rep 2014;14:415-421.

20 Suojalehto H, Lindström I, Majuri ML, Mitts C, Karjalainen J, Wolff $\mathrm{H}$, Alenius $\mathrm{H}$ : Altered microRNA expression of nasal mucosa in long-term asthma and allergic rhinitis. Int Arch Allergy Immunol 2014;163:168-178.

21 Shaoqing Y, Ruxin Z, Guojun L, Zhiqiang Y, Hua $\mathrm{H}$, Shudong $\mathrm{Y}$, et al: Microarray analysis of differentially expressed microRNAs in allergic rhinitis. Am J Rhinol Allergy 2011; 25:e242-6.

$22 \mathrm{Lu}$ TX, Rothenberg ME: Diagnostic, functional, and therapeutic roles of microRNA in allergic diseases. J Allergy Clin Immunol 2013;132:3-13.

23 Suojalehto H, Toskala E, Kilpeläinen M, Majuri ML, Mitts C, Lindström I, et al: MicroRNA profiles in nasal mucosa of patients with allergic and nonallergic rhinitis and asthma. Int Forum Allergy Rhinol 2013;3:612620 